\title{
O PROGRAMA DE SEMENTES CRIOULAS NO ÂMBITO DO MOVIMENTO DE MULHERES CAMPONESAS EM SANTA CATARINA - BRASIL
}

\section{LE PROGRAMME DES SEMENCES CRÉOLES DANS LE CADRE DU MOUVEMENT DES PAYSANNES A SANTA CATARINA - BRÉSIL}

\begin{abstract}
Sirlei Antoninha Kroth Gaspareto
Doutora em Desenvolvimento Regional. Professora da Universidade Comunitária da Região de Chapecó (UNOCHAPECÓ) e militante do Movimento de Mulheres Camponesas - MMC sirlei@unochapeco.edu.br

Virginia Elisabeta Etges Doutora em Geografia Humana pela USP. Professora do Programa de Pós Graduação da Universidade de Santa Cruz do Sul - PPGDR/UNISC etges@unisc.br
\end{abstract}

Erica Karnopp Doutora em Geografia pela Universidade de Tübingen - Alemanha. Professora do Programa de Pós Graduação da Universidade de Santa Cruz do Sul - PPGDR/UNISC erica@unisc.br

\section{Resumo}

O Movimento de Mulheres Camponesas (MMC), desde o início dos anos 1980 na região oeste de Santa Catarina, foi construindo experiências e práticas alternativas na perspectiva de um Projeto de Agricultura Camponesa, agroecológica e feminista, em conjunto com outras organizações e movimentos autônomos de mulheres do meio rural existentes em outros Estados do Brasil. Este relato de experiência apresenta o Programa de Sementes Crioulas no âmbito do MMC buscando compreender como as práticas históricas e sociais das mulheres camponesas em movimento condicionam a produção de saberes e de fazeres no MMC no oeste catarinense. Tomamos como referência algumas reflexões sobre a perspectiva materialista da história, em articulação com aportes teóricos de diferentes autores, utilizando a técnica do "círculo epistemológico de cultura", que possibilitou às mulheres relatarem suas experiências ao mesmo tempo em que foram pensando sobre suas realidades e elaborando propostas alternativas para a agricultura camponesa, não mais vista apenas como uma forma de produzir no campo, mas como um modo de viver individual e coletivamente, gerando autonomia. Essa outra perspectiva prevê, ali, a possibilidade da diversificação na produção com base na troca, no intercâmbio, na socialização. Os elementos do que produzir, como produzir, quando produzir, para quem produzir, vão sendo demarcados por caminhos abertos, dinâmicos, que se refazem e são ressignificados, ao mesmo tempo em que despertam na própria experiência um novo esperançar.

Palavras-chave: Mulheres camponesas. Sementes crioulas. Círculo epistemológico de cultura. Santa Catarina. 


\section{Résumé}

Le Mouvement des Femmes Paysannes (MMC), depuis le début des années 1980 dans la région ouest de Santa Catarina, construit des expériences et des pratiques alternatives dans la perspective d'un Projet d'Agriculture Paysanne, agroécologique et féministe, avec d'autres organisations et mouvements autonomes des femmes rurales existant dans d'autres États du Brésil. Ce rapport d'expérience présente le programme de semences créoles dans le cadre de la MMC, qui cherche à comprendre comment les pratiques historiques et sociales des paysannes en mouvement conditionnent la production de connaissances et du savoir faire dans le MMC, à l'ouest de Santa Catarina. Nous prenons comme référence quelques réflexions sur la perspective matérialiste de l'histoire, en articulation avec les contributions théoriques de différents auteurs, en utilisant la technique du «cercle épistémologique de la culture», qui permettait aux femmes de raconter leurs expériences tout en réfléchissant à leurs réalités, faire des propositions alternatives pour l'agriculture paysanne, considérée non plus comme une forme de production sur le terrain, mais comme un mode de vie individuel et collectif, générant de l'autonomie. Cette autre perspective antecipe la possibilité de diversifier la production basée sur l'échange et la socialisation. Les aspects de ce qu'il faut produire, comment produire, quand produire, pour qui produire, sont marqués par les voies ouverts et dynamiques qui sont reconstitué avec une nouvelle signification, en suscitant un nouveau espoir dans la propre expérience.

Mots-clés: Paysannes. Semences créoles. Cercle épistémologique de la culture. Santa Catarina.

\section{Introdução}

O presente relato de experiência é resultado da tese de doutorado ${ }^{i}$ que analisou a construção de saberes no Movimento de Mulheres Camponesas - MMC, a partir do Programa de Sementes Crioulas, no oeste de Santa Catarina - Brasil. Partimos do princípio de que toda prática social produz conhecimento, desconstruindo a ideia de que haja apenas um conhecimento. Esse processo recupera e ressignifica valores presentes nas práticas e saberes tradicionais dos povos negros, caboclos, indígenas, bem como as lutas de resistência desses povos e das Ligas Camponesas, que sofreu impactos contextualizados no processo de desenvolvimento capitalista no campo brasileiro.

As mulheres camponesas em movimento no MMC, antes invisibilizadas, na medida em que foram construindo práticas, elaborando saberes, foram também ressignificando e assumindo-se em sua identidade camponesa feminista. Participaram e criaram estratégias de lutas específicas e gerais, individuais e coletivas, de produção e reprodução da vida, na militância e fora dela. Cursos, trabalhos de base, lutas específicas e gerais, conjunturais e estruturais constituíram e fortaleceram a construção de saberes 
que foi gradativamente possibilitando novas formas de enfrentar as contradições vividas no campo.

Nesse contexto, através da práxis, foram demarcando outras perspectivas, fazendo com que essa experiência fosse repercutindo no território, ali se fortalecendo e ganhando novos contornos. A questão de pesquisa que nos colocamos foi: Como as práticas históricas e sociais das mulheres camponesas em movimento condicionam a produção de saberes e de fazeres no MMC no oeste catarinense? A partir deste problema, colocamos as seguintes questões norteadoras: Como a experiência de luta das Mulheres Camponesas em movimento na região oeste catarinense repercute em suas visões acerca da produção de saberes historicamente produzida? Como a práxis das Mulheres Camponesas em movimento repercute na configuração do território na região oeste catarinense? Os saberes veiculados pelas práticas das Mulheres Camponesas no oeste catarinense apontam para uma epistemologia da resistência?

À luz dessa problematização, fizemos as seguintes ponderações: i) interpretamos os significados e a fundamentação teórico-analítica dos conceitos buscando chegar à compreensão que a experiência das mulheres camponesas em movimento no $\mathrm{MMC}$, em seus 34 anos de existência, construiu outra perspectiva epistemológica; ii) investigamos o contexto no qual os conceitos interpretativos foram sendo criados e sua repercussão na experiência do $\mathrm{MMC} / \mathrm{SC}$, visando compreender como as mulheres em foram avançando para a compreensão dessa outra perspectiva epistemológica; iii) confrontamos a configuração da experiência fundamentada em autores como Thompson (1981), Saffioti (2004), Freire (2014), entre outros, mediante os resultados da pesquisa de campo, os arquivos do MMC/SC e o referencial de análise teórico-metodológico adotado.

Para demonstrar como esse processo foi se materializando, optamos pela abordagem materialista histórico-dialética. Para a coleta de dados, os procedimentos adotados foram autobiografias, entrevistas e Círculos Epistemológicos de Cultura CECs, que foram registrados e acompanhados no diário de campo. As próprias mulheres camponesas, durante a participação nos CECs, foram apresentando impasses, dificuldades e desafios enfrentados no dia a dia. Junto a isso, utilizamos fontes do Centro de Memória do Oeste de Santa Catarina - CEOM e do próprio Movimento, entre eles, informativos, arquivos, cartilhas, sítios eletrônicos, além da pesquisa bibliográfica.

Figura 1 - Municípios Sedes de Regionais do MMC participantes da pesquisa 


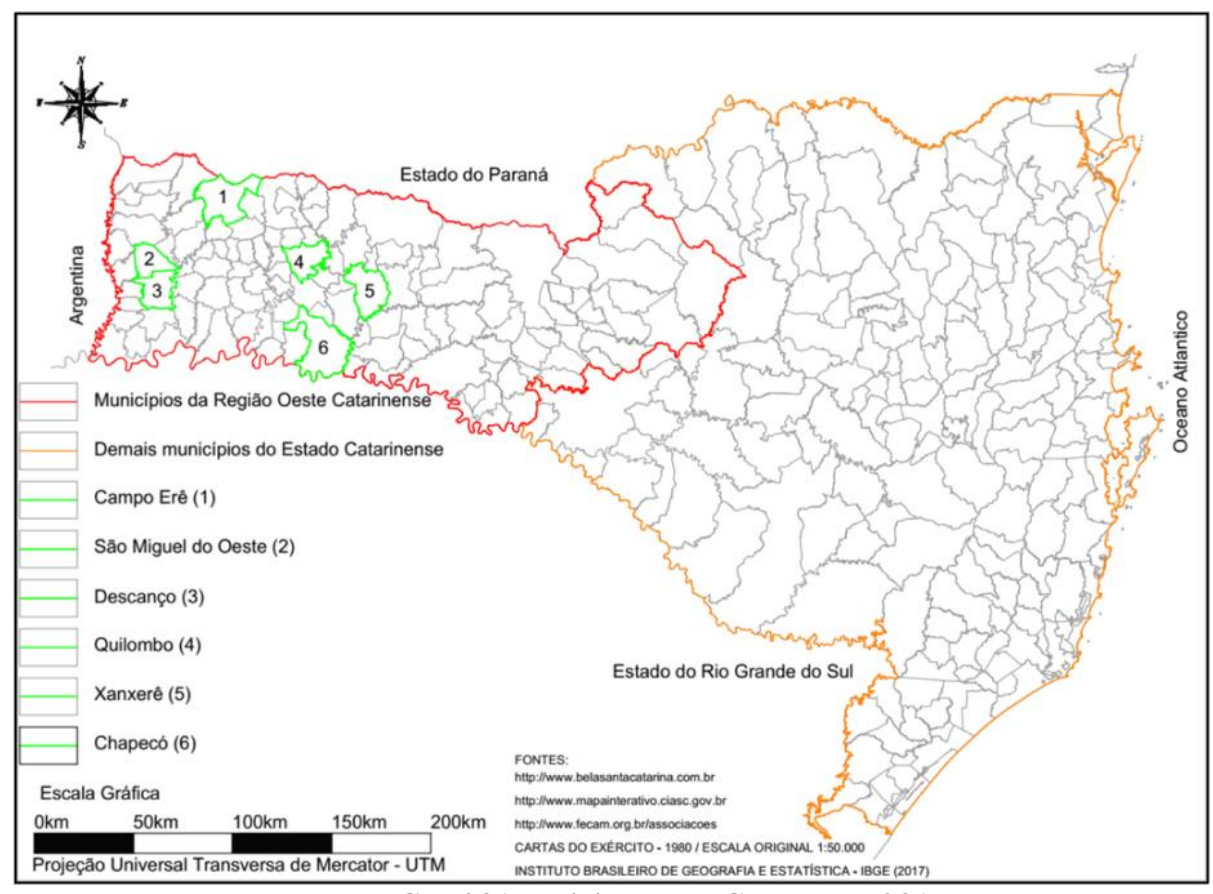

Fonte: IBGE, 2017. Elaboração: Gaspareto, 2017.

O recorte do tema tem como foco o Programa de Sementes Crioulas do MMC/SC na medida em que ele se efetiva como uma práxis das mulheres camponesas do MMC que, ao repercutir na configuração do território na região oeste catarinense, pode ser entendido como gerador de benefícios sociais e ambientais, ao mesmo tempo em que promove resultado financeiro positivo de forma sustentável, bem como gera novos conhecimentos.

Mostramos como e quando o Programa surgiu, seus objetivos e alguns significados expressos nas narrativas da pesquisa, em diálogo com o referencial teórico. Da mesma maneira demonstramos que essa experiência em construção nesse Movimento explicita o território como lugar da práxis. É ali que as pessoas vivem, criam suas relações e buscam construir formas diferenciadas para uma vida melhor.

\section{O programa de sementes crioulas de hortaliças e as perspectivas das mulheres no campo}

A realidade analisada nesta pesquisa traz as marcas das consequências da modernização da agricultura que impôs aos trabalhadores em geral, e às mulheres em particular, sérias consequências. O Programa de Sementes Crioulas de Hortaliças foi assumido no MMC em 2001, a partir de um debate que o Movimento vinha fazendo "[...] sobre a soberania alimentar, garantia das sementes como patrimônio da 
humanidade, valorização de práticas acumuladas fundamentada na agroecologia em oposição aos alimentos transgênicos" (ADÃO, 2009, p. 76). Não é uma proposta isolada das mulheres camponesas do MMC. Essas práticas agroecológicas com sementes crioulas de hortaliças e plantas medicinais, "[...] que vieram a ser potencializadas e politizadas no MMC, fazem parte do resultado de intensos debates nas diferentes instâncias do mesmo, bem como em espaços de articulação e alianças com outras organizações" (CINELLI; CONTE, 2014, p. 2).

O MMC, no contexto das tensões vividas no campo, começou uma luta em defesa de um projeto popular de agricultura camponesa agroecológica. As decisões foram tomadas durante a realização da VIII Assembleia Estadual de 2001. O documento do Movimento elenca várias razões que motivaram as mulheres a lutar nesta direção, entre as quais destacamos:

1) Projeto Popular de Agricultura; 2) Pela viabilização de políticas agrícolas, como o crédito especial para mulheres; 3) Pela defesa, preservação, conservação da água e das sementes crioulas patrimônio da humanidade, como garantia da soberania alimentar; 4) Pelo direito à terra por meio da Reforma Agrária e fim do latifúndio estabelecendo o limite de propriedade. (MMC, 2004, p. 5).

As narrativas são reveladoras de como esse processo foi sendo construído pelas mulheres em movimento no MMC/SC. Zenaide contou-nos que:

O Programa de Sementes vem desde o início do Movimento, é consequência do modelo. No ano 2000, realizamos Seminários de agroecologia que discutiam sobre o modelo químico $\mathrm{X}$ agroecologia. Foi um debate amplo. Neste meio tempo, em 2001, realizamos o acampamento em Florianópolis assumindo a campanha contra os transgênicos. Fizemos a luta contra os transgênicos, agrotóxicos. Em Janeiro de 2000, 2001, 2002 fiz o curso de Realidade Brasileira em Juiz de Fora, MG. No Fórum Social Mundial é lançada em Porto Alegre a campanha Sementes Patrimônio da Humanidade. A Assembleia do MMA/SC realizada em Concórdia aconteceu em novembro de 2001. Lá em Concórdia resolvemos fazer um Mercadinho natural. Discutimos com as mulheres durante o período de preparação se íamos comprar, ou levar os alimentos. Deu muita discussão para organizar o mercado. Na Assembleia participou mais de 500 mulheres. Achavam que não ia ter comida, mas cada uma levou e deu o suficiente para todas. Voltamos de lá convencidas de que eram as sementes e que o caminho era a agroecologia, mas não sabíamos como fazer. 2000- 2002. (CEC, Zenaide, Marema/SC, 2017).

Observamos que houve um intenso trabalho de base que foi motivando as mulheres a pensarem propostas concretas para enfrentar a crise do modelo químico de agricultura. Além de inúmeros seminários, acampamentos, cursos, reuniões, as mulheres participaram do Fórum Social Mundial, espaço importante para o intercâmbio 
de experiências. Acrescenta Zenaide:

No planejamento ainda nós não sabíamos como fazer. Depois fizemos mais um Seminário lá no Sagrado Coração de Jesus. Teve o Curso da Realidade Brasileira em Juiz de Fora. Campanha da CLOC - Sementes Patrimônio da Humanidade a serviço dos Povos. Junto com isso tinha a festa das sementes crioulas em Anchieta/SC. O forte era sementes de milho que vinha de outros Movimentos. Daí no MMC o questionamento: E nós, qual será a nossa contribuição nessa campanha para o Projeto Popular de Agricultura Camponesa? (CEC, Zenaide, Marema/SC, 2017).

A partir dos questionamentos sobre a contribuição das mulheres camponesas para pensar um Projeto Popular de Agricultura Camponesa, elas intensificaram suas práticas com trocas de sementes. Notamos que:

\begin{abstract}
Com um saber que lhe é próprio, o Movimento já vivia uma prática social comum entre as mulheres, ou seja, as trocas de sementes e mudas de uma enorme variedade de espécies, e, com isso foi acontecendo a recuperação e multiplicação das espécies crioulas, visto que muitas delas se perderam devido ao modelo de agricultura baseado na Revolução Verde, a qual infringiu pesados investimentos em híbridos e agrotóxicos, destruindo os policultivos regionais. (CINELLI; CONTE, 2014, p. 3).
\end{abstract}

As deliberações coletivas que as mulheres haviam assumido no Movimento foram transformadas em forma de compromissos próprios sob a responsabilidade de cada participante.

No CEC realizado em São Miguel D'Oeste/SC, Iraci fez questão de destacar que “[...] os debates iniciaram em 1997/98. As mulheres estavam preocupadas com os transgênicos. As sementes iam se acabar. O que fazer? Havia doenças causadas pela má alimentação.” (CEC, Iraci, São Miguel D’Oeste/SC, 2017).

\title{
Em Santa Catarina, sementes crioulas de hortaliças - por quê?
}

As mulheres camponesas começaram a pensar em como fazer o Programa, onde iniciar. Diz Iraci: "Surgiu a grande ideia das sementes crioulas de hortaliças onde o estudo era em torno da mãe terra, água, sementes. Nesse momento, houve o trabalho de busca e troca das sementes entre as mulheres.” (CEC, Iraci, São Miguel D’Oeste/SC, 2017). Carmem explicou que logo foram destacando que deveria ser "ao redor da casa". Acrescentou: "Começamos a pensar como fazer um programa que tivesse o domínio das mulheres. A horta, assim, toma a forma da resistência das mulheres. Se era agroecologia naquele momento as mulheres não iam entender. Pensamos nas sementes por ser produzida na horta." (CEC, Carmem, Chapecó/SC, 2017).

Estudos de Cinelli e Conte (2014) revelaram que: 
O processo formativo das mulheres camponesas que costurava o elo entre práticas com outros conhecimentos teóricos, perpassava desde estudos sobre solos, sua constituição, até a produção agroecológica, propriamente dita e as condições para tal. Outra prática cultural consistia nas maneiras de colheita, secagem e armazenamento das sementes, dada a importância da autonomia camponesa/das mulheres para a produção de alimentos saudáveis e a garantia da soberania alimentar. (CINELLI; CONTE, 2014, p. 4).

Nesse processo de luta, as próprias mulheres se deram conta de que as sementes que ainda restam estão nas mãos de mulheres camponesas:

Eu lembro que na época a gente falava que o que nós ia fazer era para as 'miudezas' para a subsistência (era assim que se chamava na época), isso era nós que fazia. Depois com o tempo a gente viu que era autossustento, daí a gente viu que não era mais miudeza. Daí a gente começou mudar tudo isso. Daí que veio a ideia de projeto popular de agricultura camponesa. Aí quando a gente foi pro resgate a gente viu que quem tem essas sementes eram os camponeses. Não eram os latifundiários. Não era o médio produtor, nem todos da agricultura familiar integrada ainda tinha sementes. A gente perdeu bastante, porque comprava tudo. Fomos ver que as sementes estavam nas mãos das mulheres. (CEC, Zenaide, Marema/SC, 2017).

As mulheres foram se dando conta da importância da alimentação saudável que fazia enfrentamento aos alimentos industrializados. No CEC realizado em Chapecó (SC), ao tratar sobre esta mesma temática, Carmem ponderou que a definição pelo Programa de Sementes Crioulas de Hortaliças encontra sua origem também no enfrentamento às práticas que se difundiam na agricultura, tentando inculcar nas famílias do campo os valores da industrialização, do químico, como base da alimentação. Assim fala Carmem:

O programa das sementes crioulas de hortaliças não aconteceu do nada, foi se construindo a partir dos debates. Quando começou mesmo nós fomos nos dando conta que a EPAGRI levava receita de margarina, a maioria era comprado e desvalorizava o que nós tinha. Era uma época que a gente deixava as frutas apodrecerem e ia comprar ki-suco no mercado. O Movimento começou fazer o resgate desde o fermento caseiro. Começamos debater que devíamos usar a manteiga e a nata no lugar da margarina. Suco natural no lugar do Ki-suco e do refrigerante. Isso só prejudicava na nossa alimentação. Antigamente as vó produziam de tudo. Daí que fomos percebendo que nós já tinha perdido várias sementes. (CEC, Carmem, Chapecó/SC, 2017).

Além da ligação com a terra, com a produção de alimentos saudáveis, esse processo foi mostrando que estava nascendo ali algo que é de domínio das mulheres, que está no território das mulheres. Lá elas mandam, decidem, implementam. Conforme diz Justina: "Fazer um trabalho a partir do território que era das mulheres, onde estava a autonomia das mulheres. [...] Ali as mulheres tinham condições de decidir e fazer.” Assim, começaram a trabalhar oficinas por regional. "Valendo-se das técnicas de agroecologia com participação 
de outros Movimentos populares e entidades que tinham conhecimento no assunto." (CEC, Iraci, São Miguel D’Oeste/SC, 2017).

Definida a proposta de trabalho com sementes crioulas de hortaliças, sem deixar de lado as plantas medicinais, as flores e outras espécies, o desafio que se apresentava a partir daí era a necessidade de planejar o trabalho. Esclarece Carmem:

\begin{abstract}
A gente se perguntou: Como montar o programa? Precisamos de técnico, gente capacitada para nos ajudar. Procuramos a APACO que ajudou. Fizemos seminários em cada regional, daí fizemos nos municípios para tratar sobre o resgate de hortaliças, daí veio as outras sementes que tratam da nossa alimentação. Foi feito esse resgate e melhoramento de sementes em 78 municípios de SC. Por um período de 6 a 9 anos. Cada ano nós fazia três oficinas em cada município. Hoje as mulheres acostumaram, aonde vão levam sementes para repartir, trocar com as companheiras. Pegou mesmo a troca de experiência. (CEC, Carmem, Chapecó/SC, 2017).
\end{abstract}

Durante os CECs as mulheres demonstraram satisfação considerando que, ao avaliar essa experiência, acertaram em suas estratégias ao mesmo tempo em que fizeram outros apontamentos. Diz Justina: “A construção coletiva dos objetivos, princípios e valores do programa de sementes a partir do Movimento, nos deu rumo. Não era produzir por produzir. Estudar, produzir e lutar. Nós tínhamos clareza do que queríamos.” (CEC, Justina, Marema/SC, 2017).

\title{
Os objetivos iniciais do programa de sementes crioulas
}

Nos estudos realizados por Munarini e Collet (2007), consta que o objetivo geral do Programa de Sementes Crioulas de Hortaliças é:

Construir com as mulheres camponesas a experiência prática e teórica de recuperação, produção e melhoramento de sementes crioulas de hortaliças, como ação concreta das mulheres camponesas na construção do projeto de agricultura camponesa a partir dos princípios de agroecologia. (MUNARINI; COLLET, 2007, p. 4).

Os objetivos específicos podem ser agrupados em três grandes eixos: 1) Problematizar as relações patriarcais de gênero na família, no trabalho, na produção e na relação social com o ambiente; 2) Denunciar o modelo capitalista transnacional e alertar sobre as consequências dos alimentos transgênicos, dos químicos e industrializados; 3) Construir um projeto de agricultura popular camponês fundamentado na agroecologia, construindo outros saberes e outra perspectiva epistemológica, considerando outras tecnologias que venham a contribuir para a produção de sementes crioulas como garantia do alimento saudável tanto para as 
gerações atuais como futuras.

Esse programa de sementes crioulas de hortaliças foi uma das estratégias encontradas pelo Movimento que, na experiência, constitui-se como prática em defesa do projeto de agricultura camponesa agroecológica, cuidando das questões ambientais. A partir dessa estratégia as mulheres começaram a reelaborar suas perspectivas em relação ao campo. Elas foram buscando conhecer outros jeitos de fazer agricultura a partir dos estudos e metodologias elaboradas no Movimento.

O primeiro passo foi olhar o que colocávamos na mesa: alface, batatinha, feijão [...] Nos damo conta que tínhamos pouco coisa na mesa. [...] daí vimos que o solo não tava bem, começamos ir lá pra estudar, pra aprender. Daí todo o cuidado porque tinha muito bichinho. Saímos em busca do restinho que ainda se poderia encontrar nas companheiras mais velhas, porque com a Revolução Verde, nós mulheres, nos desinteressamos de cuidar das nossas sementes. Ali, voltamos para casa com o desafio de recolher e começar cuidar da semente. [...] depois veio os cursos, as oficinas, a partilha do conhecimento. E assim nós fazia o estudo e vinha pra prática, não foi fácil conhecer o solo, melhorar as sementes, era preciso várias experiências. (CEC, Lourdes, Marema/SC, 2017).

Justina falou sobre como se dá o processo metodológico no MMC:

A metodologia do estudo que vai pra prática, volta para o estudo e retorna para a prática. [...] Fizemos seminário de Curitibanos, deu uma esparramada de sementes nas regionais, depois os municípios, junto fazíamos curso na Via Campesina. Passou a ser uma prática. [...] Grandes atividades para dar visibilidade ao resultado das sementes. [...] O planejamento do material de estudo, desde o conhecimento do solo, das plantas, produção, colheita, armazenamento. (CEC, Justina, Marema/SC, 2017).

As mulheres em movimento foram avançando na construção de uma metodologia popular dita por elas, feminista camponesa. Isso significa dizer - uma metodologia feita pelas mulheres a partir de suas realidades. O que elas haviam debatido no espaço do Movimento, quem participava dos encontros tinha que voltar para suas casas, fazer na prática e, ao retornar, deveriam trazer o que conseguiram fazer em suas propriedades, socializando as dificuldades e o que fizeram para superá-las. Assim, “[...] cada uma buscava fazer análise do solo na sua propriedade e a gente fazia isso através das plantas [...] indicadoras que é o método popular, né?" (CEC, Zenaide, Marema/SC, 2017). Esse processo era ligado ao trabalho e organização mais geral do Movimento em diálogo com outros Movimentos.

[...] começamos com os seminários regionais, daí as mulheres tinham que ir pros municípios. Junto com isso vêm os cursos relacionados à Via Campesina. Teve o curso não só em Lapa/PR, mas em Pontão/RS, Ronda Alta/RS e nossas mulheres foram. Eram cursos relacionados à agroecologia. 
A partir dessas escolas que era junto com os Movimentos tivemos oportunidade de ir a vários debates de formação pra nós, pras dirigentes, pra aprender. (CEC, Justina, Marema/SC, 2017).

Conforme observamos, essas mulheres camponesas foram, pouco a pouco, retomando as práticas de produção, recuperação e melhoramento das sementes crioulas de hortaliças. Nesse processo, foram também redescobrindo o valor do seu trabalho, das práticas e dos saberes. Começaram a discutir um projeto de agricultura camponesa agroecológica dentro de uma visão mais ampla, não apenas referindo-se à produção. Não se trata apenas de um simples "Programa", mas de uma experiência de práticas e saberes que vai apontando outros sentidos, outros significados para a compreensão do mundo camponês na visão de mulheres camponesas.

Neste projeto, o MMC procura difundir e apoiar o manejo de sementes crioulas nas comunidades sob a ótica da promoção do ativismo feminista, viabilizando uma agricultura com maior respeito à natureza e valorização do conhecimento local para a garantia de uma base alimentar saudável em oposição ao modelo monocultor. (MUNARINI; COLLET, 2007, p. 4-5).

O modelo monocultor de que tratam as autoras representa o projeto capitalista de desenvolvimento da agricultura familiar e camponesa no Sul do Brasil. Esse "manejo de sementes crioulas" explicita uma dialética da dominação - da resistência - da emergência de diferentes perspectivas de saberes, conhecimento, que se coloca na relação com a própria experiência de lutas dessas mulheres, cujas histórias são condicionadas por trajetórias de negação/resistência/afirmação.

Para Cinelli (2012), a partir do programa de sementes crioulas do MMC/SC, há uma experiência de libertação das pessoas envolvidas em suas dinâmicas, que mexe com a autonomia das mulheres. Nesse sentido, a fala de Noeli é esclarecedora:

Esse debate da recuperação das sementes crioulas traz uma importância fundamental no sentido de trabalhar a emancipação das mulheres que a partir da experiência do projeto de agricultura camponesa, a partir do programa de sementes crioulas as mulheres vão construindo autonomia. Vão construindo renda, vão construindo outras possibilidades de vida no campo. Então a partir desse processo, dessa proposta que o MMC veio trabalhando, dessa troca de saberes entre as mulheres onde uma coloca na prática depois traz e socializa com o grupo, esse programa proporcionou visitas a experiências que deram certo, então, nesse momento, essa questão é fundamental nesse sentido pra trabalhar a questão da emancipação. [...]. (Entrevista, Noeli, Chapecó/SC, dez. 2016).

A luta por emancipação das mulheres camponesas também é um processo que está em construção. Integra várias dimensões que vai desde a renda, enquanto possibilidade para o viver com dignidade no campo, passa pela troca de saberes que se efetiva nos 
intercâmbios realizados, até a elaboração de uma concepção de luta contrária aos interesses do capital. Conforme Munarini e Collet (2007), em Santa Catariana, as mulheres do MMC estavam produzindo sementes em 70 municípios, o que já indicava uma experiência significativa que motivou a "Campanha Nacional pela Produção de Alimentos Saudáveis", visando a promoção da soberania alimentar, entre outros objetivos do Movimento. Trata-se de uma relação direta com as sementes presente no cotidiano das mulheres.

Boni (2012), em sua tese De agricultoras a camponesas: o Movimento de Mulheres Camponesas de Santa Catarina e suas práticas, ao tratar sobre as práticas do Movimento, destacou que o programa de recuperação de sementes crioulas de hortaliças do MMC/SC se constitui em um fator determinante para garantir a segurança e soberania alimentar, comprovando que diferentes espécies e variedades de sementes, concebidas pelo Movimento como patrimônio dos povos a serviço da humanidade, ainda estão de posse das mulheres. Mostra que, com a modernização da agricultura, não apenas as sementes crioulas foram sendo desvalorizadas e perdendo espaço para as sementes híbridas e transgênicas, mas impõe-se uma ideia de que a "ciência", representada pelo modelo químico, é mais importante que o conhecimento tradicional dos povos.

As sementes, os saberes produzidos e recuperados pelas mulheres camponesas são ressignificados e adquirem relevância, visto que reportam aos acúmulos de ancestrais, reforçam perspectivas históricas, lembram diferentes sociedades, explicitam culturas e identidades variadas, resistem às formas de dominação e criam alternativas para uma vida melhor, mesmo que, muitas vezes, sejam desqualificados e considerados inferiores por visões hegemônicas, patriarcais e eurocêntricas. Observamos que as práticas com sementes crioulas a partir das mulheres camponesas em seus territórios possibilitaram a elaboração de outros conhecimentos, outras concepções, e esse processo vai construindo outras perspectivas epistemológicas.

\section{O território como lugar da práxis}

Para pensar sobre as repercussões da práxis das mulheres em movimento no território, destacamos inicialmente algumas considerações em relação ao conceito de território, tendo em vista que este se constitui enquanto lugar da práxis. É um conceito que também está em disputa. É no território que interagem diferentes sujeitos e ali eles 
próprios fazem-se, ao mesmo tempo em que vão construindo significados para suas experiências. No século XXI, elementos novos vão se colocando, na medida em que vai se construindo uma maior tomada de consciência sobre o território pelo mundo todo. Entram em cena outras concepções a partir da dimensão territorial dos processos produtivos, culturais, sociais, entre outros. Durante a pesquisa de campo, as mulheres foram também se pronunciando em relação as suas mais diversas compreensões acerca do território. Carmem foi incisiva:

\begin{abstract}
O território das mulheres não existe. Como o território é um lugar, esse pode ser tanto para mulheres como para homens. Mas na sociedade muitas vezes as mulheres fazem seu lugar, muitos dizem que lugar de mulher é em casa! Então as mulheres acabam ocupando seu lugar privado, ficam em casa, vão à vizinha e na igreja. E repetem isso sempre, formando esse como 'o seu lugar'. Outras, porém mais ousadas ocupam outros espaços, participam da comunidade, na prefeitura, no sindicato, nos conselhos, nos movimentos sociais, no MMC, então, essas ocupam o lugar público, nesse território tem mais espaços de formações, participação, adquire conhecimento e se faz liderança. (CEC, Carmem, Chapecó/SC, 2017).
\end{abstract}

O que Carmem está dizendo é que o território não está dado, ele é construído. Há uma construção social que passa pela experiência. Exemplifica sua intervenção mostrando que o fato da casa estar vinculada ao espaço privado delegado como "lugar" atribuído à mulher não significa que este é o território das mulheres. Em sua definição, Carmem, quando se refere à dimensão do "público", mostra a dinâmica do fazer-se no território. Por isso mesmo, afirma: "Território das mulheres não existe".

O território passa a ser entendido como "um espaço onde é possível construir novas relações". Santos (2010) nos alerta sobre esse tempo de estagnação que estamos vivendo, frente às possibilidades de pensar processos de transformação social, e argumenta sobre a necessidade de uma globalização contra hegemônica, que, em seu ponto de vista, já está sendo construída a partir dos movimentos sociais e grupos organizados. Como podemos ver nas narrativas, a dimensão de território é aqui compreendida não apenas sob o ponto de vista geográfico, nem mesmo aquele delimitado por Instituições Governamentais, a exemplo do que concebe o IBGE, mas pela força dos diferentes sujeitos que intervindo nas realidades, vão produzindo diferentes significados oriundos de suas experiências, centralmente na busca de encontrar sentidos para o seu viver.

Assim, a categoria território nessa pesquisa permite-nos pensar a partir da organização dos ecossistemas, das sociabilidades, bem como de relações mais amplas, sejam elas entre campo e cidade, ou outras. Sposito (2006) afirma que há necessidade 
de se ultrapassar a visão dicotômica construída historicamente entre cidade-campo.

Explica Noeli:

Território é um espaço onde você vive, é um local. Mas eu entendo ele não só como a terra onde você constrói a tua casa, mas é um espaço de construção de relações, onde há possibilidade de construir novas perspectivas. Precisa pensar o território para além da agricultura, a questão econômica, social, política que envolve todo esse espaço que está ali colocado. É fundamental entender como ele funciona como ele se dá, pra você poder agir sobre ele construindo novas possibilidades é um espaço aberto, não é uma coisa dada. Sempre há possibilidade a partir da organização, a partir da luta. A partir do enfrentamento você construir uma nova relação porque muitas vezes, né, hoje na sociedade capitalista, patriarcal, machista, muitas vezes o território é um espaço de dominação e a partir do momento que você consegue fazer a organização a partir da luta local você tem a possibilidade de transformar essas relações. (Entrevista, Noeli, Chapecó/SC, dez. 2016).

Trata-se de analisar as relações políticas, econômicas, sociais e culturais, que, em cada espaço-tempo, orientam e dão sentido à vida no território, buscando as articulações ao invés da setorialização e do isolamento, gerando um sentido de complementariedade, de interação. Santos (2000) discute a dinâmica territorial a partir de duas dimensões vertical e horizontal.

Mostra como principalmente as grandes empresas comandam a racionalidade hegemônica global do capitalismo, transmitindo-a para a sociedade por meio das verticalidades que se espacializam no território.

Nas verticalidades, os interesses corporativos sobrepõem-se aos interesses públicos. O sistema de produção serve-se das verticalidades organizadas em redes, que se colocam a serviço de interesses exógenos, que determina e organiza a forma de ação nos lugares.

As decisões essenciais dos processos locais obedecem às motivações distantes alienando as pessoas desses lugares, enquanto na dimensão horizontal, Santos (2006) mostra que se trata de atividades e ações que possibilitam a estruturação da vida social. Nesse caso, é possível construir a união como base de vida comum.

Feito de embates, disputas, problematizações e experiências diversas o território vai sendo constituido e identificado como lugar da práxis. O processo de construção do programa de sementes crioulas de hortaliças mostra como as mulheres camponesas em movimento no MMC elaboram práticas e constroem saberes.

\section{A dimensão pedagógica do programa de sementes crioulas}


Há uma dimensão pedagógica no processo que iniciou com as sementes crioulas de hortaliças, que foi sendo ampliada e ganhou outras formas através de quintais produtivos, recuperando as flores, resgatando a criação de pequenos animais (figura 2), a produção de artesanato, as ervas medicinais, o alimento saudável. As mulheres camponesas foram aprendendo e ensinando a transformação dos remédios caseiros/alternativos (figura 3) que muito têm contribuído para as comunidades. Formaram grupos de produção de sementes (4), entre outras alternativas coletivas.

Figura 2 - Pequenos animais, propriedade de Rosalina, CEC Chapecó/SC

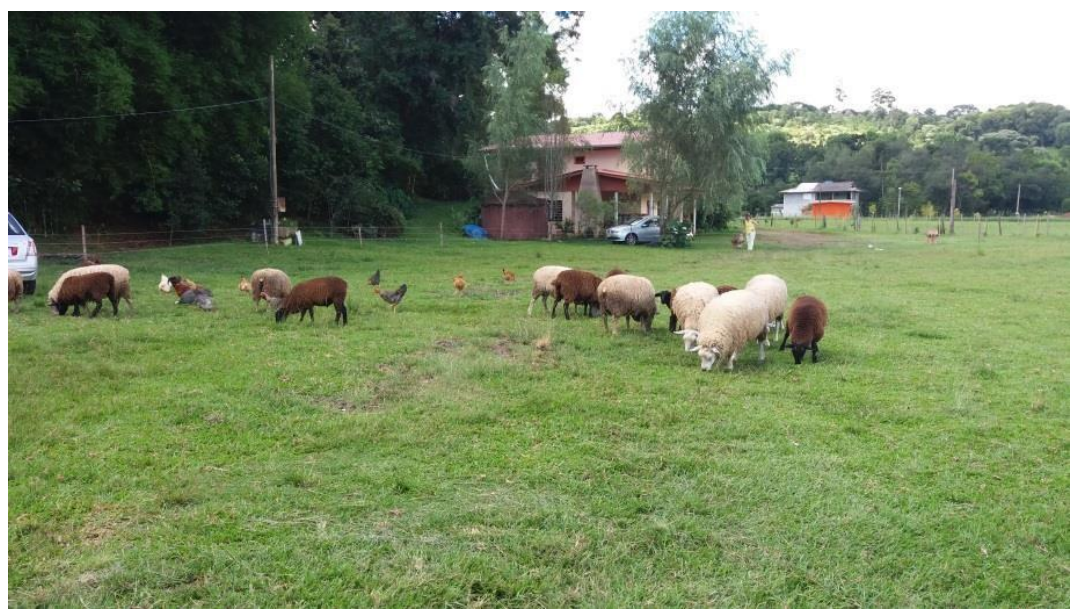

Fonte: Pesquisa de campo, 2017. Fotografia: Zenaide Collet.

As necessidades mais elementares de suas vidas lhes permitiram construir conhecimento, como a elaboração de remédios caseiros, orientados por um saber fazer recuperado por relatos e práticas de pessoas mais velhas.

Nesse sentido, o livro Pedagogia do Oprimido (2014), escrito por Paulo Freire (1 ${ }^{\text {a }}$ publicação em 1968), apresenta uma significativa contribuição para a análise da construção de saberes do MMC/SC. Da ação pedagógico-política de mulheres camponesas em movimento nasceu a possibilidade da autonomia. Não é qualquer práxis. É a práxis transformada em conhecimento, de outro jeito de viver a vida camponesa. É da ação política que vai sendo transmitido o ensinamento, passando de geração a geração. Ali "tem ciência nesse conhecimento" feito por outros sujeitos e outras pedagogias (ARROYO 2012). Assim diz Justina: [...] Aprendi outra perspectiva de vida para mim e para as mulheres.” Jacinta acrescentou: “O que a gente aprendeu é nosso. Esses saberes são nossos.” É o processo de luta e conscientização que constrói outro 
O programa de sementes crioulas no âmbito do movimento de mulheres camponesas em Santa Catarina - Brasil
Sirlei Antoninha Kroth Gaspareto Virginia Elisabeta Etges Erica Karnopp

sujeito - a mulher camponesa. Com ela nascem outros saberes e formas de aprendizado e humanização que sinalizam outras perspectivas epistemológicas.

Figura 3 - Remédios caseiros/alternativos, casa de Rosalina, Chapecó/SC

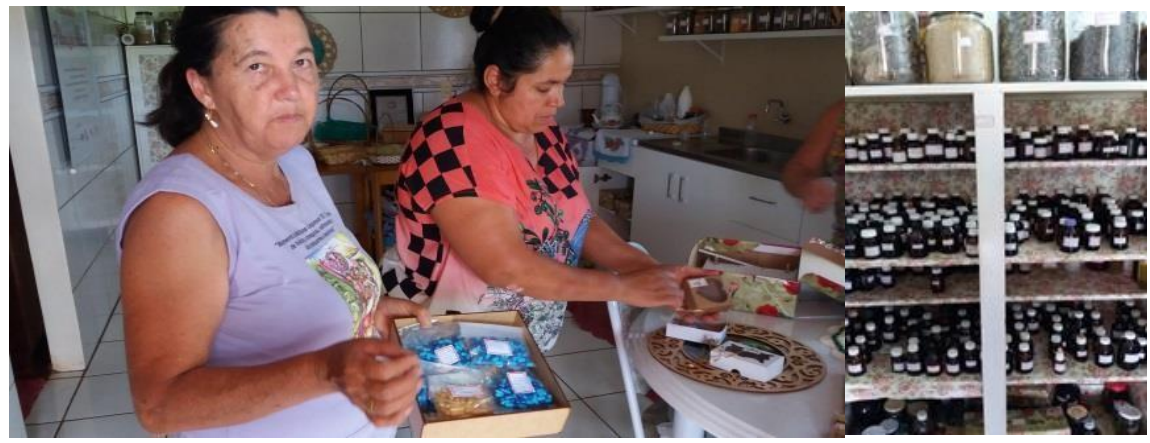

Fonte: Pesquisa de campo, 2017. Fotografia: Zenaide Collet.

No Prefácio da Pedagogia do Oprimido, Freire (2014, p. 18) desenvolve uma reflexão mais aprofundada sobre a necessidade da luta para recuperar a humanidade dos que estão em situação de opressão e servidão. Trata-se de “[...] um comportar-se do homem frente ao meio que o envolve, transformando-o em mundo humano"

Isso somente é possível por meio da ação social. Daí a importância das experiências de resistência e dos saberes que vão sendo construídos, pensados e elaborados pelos próprios sujeitos em seus processos de lutas camponesas. Freire (2014, p. 52) explica que: “[...] a práxis, porém, é reflexão e ação dos homens sobre o mundo para transformá-lo. Sem ela é impossível a superação da contradição opressãooprimido". Carmem, em sua autobiografia, deixou registrado, como, por intermédio do Programa de Sementes Crioulas de Hortaliças, as mulheres camponesas em movimento, na medida em que foram ampliando suas práticas de resgate das sementes, foram também construindo novo saberes, compartilhando valores, vivenciando relações de vizinhança.

Das sementes de hortaliça nós começamos pensar mais sobre o que nos comemos. Daí criamos o projeto da alimentação saudável no MMC. Mas daí a gente ficou pensando que precisava fazer na prática. Precisava ter as sementes nas mãos. Daí começamos a tentar com o grupo que estava a fim de fazer isso. Começamos trabalhar, demoramos 3 anos pra se afirmar como grupo. A gente se reúne uma vez por semana, 15 participantes. Dividimos em 03 mulheres pra fazer o manejo das semeaduras. As 05 mulheres que vem plantam o que precisa nas bandejas que fica para todo grupo e levam o que precisam pra horta delas. Cada uma tem sua horta individual. O manejo diário é uma família que faz. O grupo todo se reuniu pra organizar a produção de semente. (CEC, Carmem, Chapecó/SC, 2017).

Continua Carmem: 
Ficou assim: Cada mulher se responsabilizou de produzir duas espécies de sementes (alface - nós temos 3 tipos, rúcula, brócolis), não ficamos só nas hortaliças, estendemos pra outros tipos de alimento como abóbora, melancia, fisales, ibisco, tomate de árvore, crotalária, alfafa [...] o objetivo é manter a estufa com as nossas próprias sementes, recuperadas por nós. Primeiro lugar as mulheres acharam que a verdura da semente crioula é mais gostosa. A gente sabe o que tá consumindo. E uma incentiva a outra pra ter a horta cheia, bonita. Horta bonita mesa cheia e família feliz. E os homens começaram participar. Quando tá chovendo que nos fizemos reunião eles vêm tudo lá participar. (CEC, Carmem, Chapecó/SC, 2017).

Figura 4 - Grupo de produção de sementes crioulas, Chapecó/SC
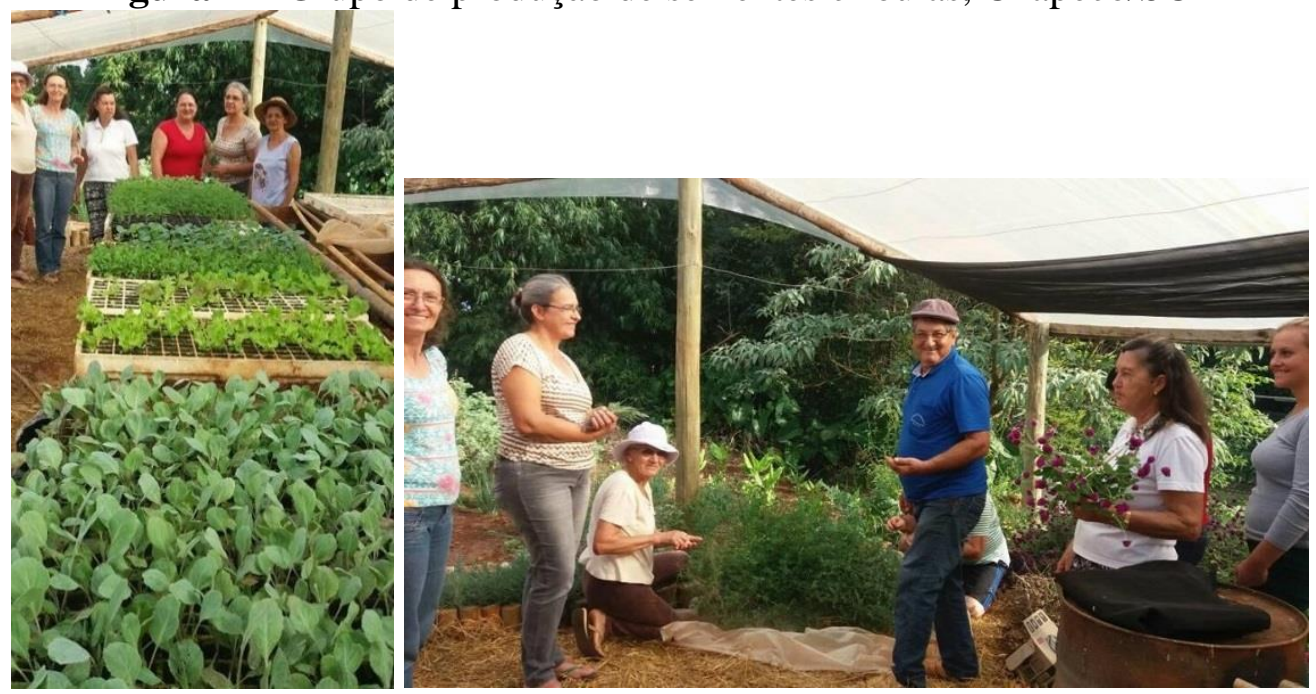

Fonte: Pesquisa de campo, 2017. Fotografia: Carmem Munarini.

Observamos que nesse processo as mulheres criam suas estratégias próprias para efetivamente chegar ao manejo das semeaduras, feito coletivamente, inaugurando um sentido de reciprocidade em cada uma de suas ações. Elas, ao mesmo tempo em que plantam para o grupo, levam para sua horta individual aquilo que falta. Ali vai se dando uma troca, intercâmbio movido pelos laços da partilha de saberes e de sabores. O coletivo alimenta e qualifica o individual e o individual fortalece os laços da coletividade. Cria-se uma responsabilidade que é de cada uma individualmente e de todas ao mesmo tempo. Na medida em que foram encontrando-se, reunindo-se em torno de objetivos comuns, foram conhecendo novas ideias e práticas, originando novas possibilidades para a vida.

\section{Considerações finais}

Com o Programa de Sementes Crioulas de Hortaliças, as mulheres que participaram dos CECs, de uma ou de outra maneira, produzem alimentos saudáveis, umas mais, outras 
O programa de sementes crioulas no âmbito do movimento de mulheres camponesas em Santa Catarina - Brasil
Sirlei Antoninha Kroth Gaspareto Virginia Elisabeta Etges Erica Karnopp

menos. Produzem e recuperam sementes crioulas de ervas medicinais e de flores. As necessidades mais elementares de suas vidas lhes permitiram construir conhecimento. A partir daí, as práticas de resistência foram adquirindo reconhecimento e as dimensões da vida foram ganhando proporções mais complexas e ampliadas.

O uso da técnica dos "circulos epistemológicos de cultura" possibilitou às mulheres repensarem e ressignificarem suas práticas, entendendo-as como saberes que apontam para possibilidades de contribuições em processos de democratização dos saberes/poderes, inclusive, na própria experiência em relação à vida e à agricultura camponesa.

Os saberes produzidos e recuperados pelas mulheres camponesas foram reportando-as ao encontro de acúmulos dos ancestrais que, de certa maneira, estavam sendo sufocados, escamoteados, silenciados. A experiência dessas mulheres mostrou que, nesse processo, elas foram pensando sobre suas realidades, confrontando com outras realidades e elaborando propostas alternativas. Isso lhes possibilitou a construção teórica prática própria que desvenda e propõe outra perspectiva para a agricultura camponesa, não mais vista apenas como uma forma de produzir no campo, mas como um modo de viver individual e coletivamente.

Por meio das práticas de produção, recuperação e melhoramento das sementes crioulas de hortaliças foram também redescobrindo o valor do seu trabalho. Ampliaram seus debates para além das "hortaliças" e foram discutindo um projeto de agricultura camponesa dentro de uma visão mais ampla, não se referindo apenas à produção.

Constatamos, no decorrer da pesquisa, que esse processo de construção de saberes aponta para uma perspectiva epistemológica feminista camponesa em construção, que nos leva a reconhecer que o MMC vem promovendo transformação social e ambiental, viabilizando o sustento das famílias de forma sustentável.

Concluindo, reafirmamos: a formulação e a construção da pesquisa emergem do frescor e do vigor da luta necessária no solo do sistema capitalista, apontando sempre para além dele, embora nele e, desde uma perspectiva latino-americana e caribenha, que se abre à universalização dos processos mais globais enquanto resistência, crítica e formulação utópica.

\section{Nota}

${ }^{1}$ Tese de doutorado defendida no Programa de Pós- Graduação em Desenvolvimento Regional - PPGDR, da Universidade de Santa Cruz do Sul - UNISC, com o apoio da CAPES, intitulada: A construção de 
saberes no Movimento de Mulheres Camponesas: uma análise a partir do programa de sementes crioulas no oeste de Santa Catarina - Brasil. A tese foi contemplada com "Menção Honrosa" no âmbito do Premio Capes de Tese 2018.

\section{REFERENCIAS}

ADÃO, Nilton Manoel Lacerda. Movimento de Mulheres Camponesas e a semeadura de novas perspectivas: os significados da (re) produção de sementes crioulas para as mulheres no Oeste Catarinense. 2009. Dissertação (Mestrado em Agroecossistemas) - Universidade Federal de Santa Catarina, Florianópolis, 2009.

ARROYO, Miguel G. Outros sujeitos, outras pedagogias. Petrópolis: Vozes, 2012.

BONI, Valdete. De agricultoras a camponesas: o Movimento de Mulheres

Camponesas de Santa Catarina e suas práticas. 2012. Tese (Doutorado em Sociologia Política) - Universidade Federal de Santa Catarina, Florianópolis, 2012.

CEOM - Centro de Organização da Memória do Oeste de Santa Catarina. Para uma História do oeste catarinense: 10 anos de CEOM. Chapecó: Unoesc, 1995.

CINELLI, Catiane; CONTE, Isaura Isabel. Educação popular numa experiência agroecológica no movimento de mulheres camponesas. In: ANPED SUL, 10., 2014, Florianópolis. Anais... Florianópolis: ANPED SUL, out. 2014.

FREIRE, Paulo. Pedagogia do oprimido. 57. ed. Rio de Janeiro: Paz e Terra, 2014. MUNARINI, Carmem; COLLET, Zenaide. Recuperação, produção e melhoramento de sementes crioulas de hortaliças: uma luta do MMC/SC. Revista Camponesa, dez. 2007.

SAFFIOTI, Heleieth. Gênero, patriarcado, violência. 1. ed. São Paulo: Fundação Perseu Abramo, 2004. (Coleção Brasil Urgente).

SANTOS, Boaventura S. Um discurso sobre as ciências. 7. ed. São Paulo: Cortez, 2010.

SANTOS, Milton. O papel ativo da geografia: um manifesto. Rev. Território, ano V, n. 9, jul./dez. 2000.

A Natureza do Espaço: Técnica e Tempo, Razão e Emoção, 2. ed. São Paulo: Editora da Universidade de São Paulo, 2006.

SPOSITO, Maria E. B. A questão cidade-campo: perspectivas a partir da cidade. In: (Org.). Cidade e Campo: relações e contradições entre urbano e rural. São Paulo: Expressão Popular, 2006.

THOMPSON, Edward Palmer. A miséria da teoria. Rio de Janeiro: Zahar, 1981. 
Recebido em 17/12/2018.

Aceito para publicação em 26/06/2019. 